\title{
VIOLÊNCIA CONTRA CRIANÇAS E ADOLESCENTES: SIGNIFICADOS E ATITUDES POR EQUIPES DA ESTRATÉGIA SAÚDE DA FAMÍLIA
}

\author{
VIOLENCE AGAINST CHILDREN AND ADOLESCENTS: MEANINGS \\ AND ATITUDES BY FAMILY HEALTH STRATEGY TEAMS
}

\section{VIOLENCIA CONTRA NIÑOS Y ADOLESCENTES: SIGNIFICADOS Y ACTITUDES POR PROFESIONALES DE SALUD DE LA FAMILIA}

\author{
Priscila França Zanelatto* \\ Marcelo Medeiros ${ }^{* *}$ \\ Walterlânia Silva Santos ${ }^{* * *}$ \\ Denize Bouttelet Munari ${ }^{* * * *}$
}

\begin{abstract}
RESUMO
O estudo teve como objetivo compreender os significados atribuídos por profissionais da Estratégia Saúde da Família sobre a violência contra a crianças e adolescentes; e as atitudes destes profissionais frente as evidencias de situações identificadas no contexto assistencial. Pesquisa social em saúde de abordagem qualitativa realizada entre fevereiro e setembro de 2009 com 18 profissionais de quatro equipes da Estratégia Saúde da Família em Goiânia, Brasil. Os dados foram coletados por entrevistas semi-estruturadas e analisadas na modalidade temática da análise de conteúdo, de onde surgiram as categorias "sentido da violência", "motivos para a violência", "procedimentos no atendimento às vítimas da violência" e "formas de ações preventivas". Os profissionais compreendem as questões sociais como uma das principais razões para a ocorrência da violência nas famílias, sendo as ações preventivas e encaminhamentos aos órgãos judiciais competentes ou instituições de saúde de maior complexidade as ações mais significativas.
\end{abstract}

Palavras chave: Violência doméstica, crianças, pessoal de saúde, saúde da família.

\begin{abstract}
This study sought to understand the meanings attributed by Family Health Strategy professionals on violence against children and adolescents, and their attitudes toward violence evidences noted in health care context. Qualitative social health research developed from February to September 2009 with 18 professionals of four Family Health Strategy teams in Goiânia - Brazil. Data collection was performed by semi-structured interview and analyzed through content analysis as thematic modality, that generated categories as "violence meanings"; "reasons for violence"; "procedures in dealing with victims of violence"; and "ways for preventive programs". The participant professionals understand the social issues as one of the major reasons for violence occurrence within families, being the preventive actions and reference to judicial or more complex health institutions as the most significant attitudes.
\end{abstract}

Key words: Domestic violence, children, health personnel, family health.

\footnotetext{
*Enfermeira. Secretaria municipal de Saúde, Goiânia, Goiás, Brasil. E-mail: priscilafranca@hotmail.com

** Enfermeiro. Professor da Faculdade de Enfermagem da Universidade Federal de Goiás, Goiânia, Brasil. E-mail:marcelo@ fen.ufg.br

*** Enfermeira. Professora do Curso de Enfermagem da Universidade Federal de Goiás, Catalão, Goiás, Brasil. E-mail: lanianurse@gmail.com

${ }^{x * * *}$ Enfermeira. Professora da Faculdade de Enfermagem da Universidade Federal de Goiás. Goiânia, Goiás, Brasil. E-mail: denize@fen.ufg.br
} 


\section{RESUMEN}

El estudio tuvo como objetivo comprender los significados atribuidos por profesionales de la Estrategia de Salud de la Familia sobre violencia contra niños y adolescentes; las actitudes de estos profesionales frente a las evidencias de situaciones identificadas en el contexto asistencial. Investigación social en salud de abordaje cualitativo realizada entre febrero y septiembre/2009 con 18 profesionales de cuatro equipos de Estrategia de Salud de la Familia en Goiânia, Brasil. Los datos fueron recolectados por entrevistas semiestructuradas y analizados en la modalidad temática del análisis de contenido donde surgieron las categorías "sentido de la violencia", "motivos para la violencia", "los procedimientos en la atención a las víctimas de la violencia", y "formas de acción preventiva." Los profesionales comprenden las cuestiones sociales como un de las principales razones para ocurrencia de violencia en las familias, siendo las acciones preventivas y encaminamiento a órganos judiciales competentes o instituciones de salud de mayor complexidad las actitudes mas significativas.

Palabras clave: Violencia doméstica, niños, personal de salud, salud de la familia.

Fecha recepción: 04/03/11 Fecha aceptación: 24/08/12

\section{INTRODUÇÃO}

A manifestação da violência está intimamente relacionada aos aspectos culturais, status social, faixa etária, etnia, gênero, entre outros de uma determinada sociedade. No Brasil, a violência manifesta-se nos mais diversos ambientes, sendo muito frequente a violência doméstica ou intrafamiliar, cujas vítimas preferenciais são as crianças e os adolescentes de ambos os sexos (1-4). Neste artigo partimos da compreensão do Estatuto da Criança e do Adolescente (ECA) de que a criança é o indivíduo até 12 anos de idade e adolescente aquele entre 12 e 18 anos (5).

A violência intrafamiliar é uma grave violação de direitos da criança e o adolescente, uma vez que lhes nega a liberdade, a dignidade, o respeito e a oportunidade de crescer e se desenvolver em condições saudáveis (1). Segundo alguns autores (3) a violência doméstica contra a criança e o adolescente é uma forma de submeter à força, alguém contra a sua vontade, quebrando acordos e regras que pautam as relações conferindo-lhe uma carga negativa. Pode assumir características de agressão física, sexual, negligência e psicológica (3) e, por essa razão, a violência contra a criança deve ser denunciada (6).
Nesse sentido, cabe ao profissional de saúde a tarefa de reconhecer nos casos em que atender, se estes caracterizam situações em que a criança e ou o adolescente foram ou estão sendo ou foram vítimas de alguma forma de agressão, considerando os vários tipos de violência seja física, sexual, negligência ou psicológica (7). Ao mesmo tempo, este profissional deve ter conhecimento para realizar intervenções adequadas frente à problemática, de forma integrada com os serviços disponíveis na comunidade, tais como os Comitês de Proteção à Criança e ao Adolescente, Conselhos Tutelares, Ministério Público, entre outros (4).

Estudo recente (3) mostra que a falta de notificação de casos de atos violentos contra crianças e adolescentes é decorrente de múltiplos fatores. Entre eles, são destacados o pacto de silêncio que ocorre nos lares, aceitação da punição física como medida "educativa", assim como a dificuldade de classificar os casos como de violência (3). A posição estratégica dos membros envolvidos na expansão da atenção básica de saúde, principalmente, os que atuam na Estratégia Saúde da Família (ESF), lhes permite uma visão mais concreta da situação de violência a que estão sujeitos os usuários e a própria comunidade, por promoverem ações de saúde dentro dos lares de 
sua população adstrita, o que os torna mais aptos na identificação e no enfrentamento das situações de violência (7).

No entanto, nem sempre essa é uma prática diária dos profissionais de saúde e membros das equipes da ESF, em razão da complexidade que envolve a violência e seus determinantes. Por isso, nos propusemos a realização do presente estudo, cuja construção se pautou em questões como: quais os significados atribuídos pelos membros das equipes da ESF sobre a violência contra a criança e o adolescente? Como agem os profissionais e os membros das equipes da ESF perante os casos suspeitos e confirmados de agressão contra a criança e o adolescente? As respostas a esses questionamentos poderão contribuir enquanto subsídio para o debate dessa questão, proporcionando reflexão dos profissionais de saúde e membros das equipes da ESF sobre estratégias educativas e de prevenção da violência infantil, bem como para a construção de ações que possam assegurar a assistência integral e de qualidade à família.

Com base nessas questões, o objetivo da investigação foi compreender os significados atribuídos pelos profissionais e membros das equipes da Estratégica Saúde da Família sobre a violência contra a criança e o adolescente e suas atitudes diante das evidencias das situações constatadas no contexto da atenção básica de saúde.

\section{MÉTODOLOGÍA}

A pesquisa Social em Saúde de abordagem qualitativa mostrou-se mais apropriada para o alcance do objetivo proposto, por possibilitar a observação do universo de significados, motivos, crenças valores e atitudes, dos atores sociais pertencentes ao contexto investigado. Esta modalidade de investigação busca responder de modo aprofundado e particular as questões que ocupam um nível da realidade social que não deve ser quantificada (8).

$\mathrm{O}$ estudo foi desenvolvido com quatro equipes da ESF de um distrito específico de saúde de Goiânia, escolhido por concentrar atividades de ensino, pesquisa e extensão da Universidade Federal e, mais especificamente, da Faculdade de Enfermagem, o que totalizou 18 participantes, sendo quatro médicos, quatro enfermeiros, quatro auxiliares de enfermagem e seis agentes comunitários de saúde. Para a composição do grupo de participantes foram considerados como critérios de saturação dos dados coletados por meio de entrevista individual mediada por um roteiro contendo questões semi-estruturadas, realizadas entre os meses de fevereiro a setembro de 2009. Estas questões buscaram explorar junto aos participantes os significados atribuídos por eles sobre: a violência praticada contra crianças e adolescentes e quais são os atos mais comuns por eles verificados; e, também, as ações e procedimentos para o atendimento das vítimas de atos violentos.

As entrevistas foram conduzidas pela própria pesquisadora, momento em que eram esclarecidos os objetivos da investigação aos participantes, bem como orientado aos mesmos quanto à sua liberdade de participação ou não na pesquisa e solicitada a assinatura do "Termo de Consentimento Livre e Esclarecido". Vale salientar que o projeto que originou esta pesquisa foi aprovado pelo Comitê de ética em Pesquisa Médica Humana e Animal do Hospital das Clínicas da Universidade Federal de Goiás, sob Protocolo ${ }^{\circ} 171 / 08$.

A análise dos dados foi fundamentada nos princípios Análise de Conteúdo - Modalidade Temática que "consiste em descobrir os 'núcleos de sentidos' que compõem a comunicação e cuja presença ou freqüência de aparição podem significar alguma coisa para o objetivo analítico escolhido" (9). Inicialmente procedemos à leitura exaustiva de todo o material proveniente das entrevistas, com o intuito de apreender o seu conteúdo e identificar as idéias centrais. Deste movi- 
mento emergiram os núcleos de sentido que permitiu a construção das categorias temáticas "o significado da violência"; "motivos para a violência"; "procedimentos no atendimento à vítima de violência"; e "caminhos para ações preventivas". Posteriormente procedemos à análise dos dados articulados à luz da literatura especializada. Para identificação dos trechos de falas apresentados na discussão foram adotados um código alfabético (E) seguido do número seqüencial de realização da entrevista (E-1).

\section{RESULTADOS}

De modo geral, os dados mostram que, para os sujeitos do estudo, a violência contra a criança consiste em qualquer ação que possa inibir seu desenvolvimento, constituindo-se em um abuso, covardia e absurdo, uma vez que envolve um ser indefeso. Para eles, a violência infantil ocorre, principalmente, no âmbito familiar, caracterizada pela violência sexual, a qual, sob suas perspectivas, é a forma mais grave da violência infantil. Os participantes consideram ainda a negligência como a principal violência encontrada na população de sua área de abrangência e percebem que a violência física é vista como uma forma de educar os filhos. Entretanto, alguns dos entrevistados concebem a violência infantil enquanto consequência da falta de assistência à educação, à saúde e do convívio social, entre outros problemas desta natureza.

Além disso, outras questões sociais, como o desemprego, baixa escolaridade e pobreza são consideradas, pelos entrevistados, fatores desencadeantes da violência contra a criança. Tais condições podem, segundo os sujeitos, ocasionar nervosismos, estresse familiar, falta de paciência ou ansiedade dos pais, que acabam trazendo problemas externos ao âmbito familiar, motivando a violência infantil. Alguns membros das equipes da ESF tam- bém afirmam que a falta de conhecimento das mães sobre os parceiros, a ausência de diálogo com a criança, a falta de atitudes das mães quanto à violência contra seus filhos são motivos que levam à ocorrência desta violência. As categorias identificadas a partir dos dados são apresentadas na sequência.

\section{O significado da violência}

Nesta primeira categoria, nos interessa buscar os significados da equipe, já que envolve componentes da ESF, assim, não nos preocupamos em diferenciar os significados de violência em categoria profissional, por descaracterizar o intuito da ESF de agir de forma integrada e multidisciplinar, envolvendo todos os membros da equipe. Assim, diante da percepção das equipes, os participantes afirmaram que a violência contra a criança começa dentro de casa, sendo considerada por eles como violência doméstica. Assim, abordam esta violência como maus-tratos que podem ser de ordem física (agressão, bater por motivos fúteis), psicológica (gritar, ver e ouvir os pais brigarem entre si, falar alto e manipular a criança a fazer algo que não quer), sexual e de negligência (falta de atenção, deixar a criança de lado, deixar a criança sozinha dentro de casa). Estes aspectos podem ser ilustrados nas seguintes falas dos sujeitos: Violência é o abuso, a violência doméstica, que a criança recebe dos pais, das pessoas da família (E2). Violência para mim é algum ato de agredir ou fisicamente ou psicologicamente, a negligência também, na falta de atenção, um fato que possa machucar ou fisicamente brutalmente a criança e o adolescente também, ou psicologicamente manipulando a mente, fazer alguma coisa que ela não quer (E8).

\section{Motivos para a violência}

A segunda categoria traz a perspectiva dos profissionais e dos membros das equipes da ESF para os motivos que concorrem para a 
ocorrência da violência contra a criança, que são diversificados sendo os mais abordados: os problemas sociais como o desemprego, a desinformação, a falta planejamento familiar acarretando grande número de filhos, separação dos pais, os pais e as mães se distanciando dos filhos para sustentar a família, baixa escolaridade dos pais e a pobreza como destacado no seguinte depoimento: a gente sabe que o problema social é grande, que essa crise atinge emocionalmente, socialmente, financeiramente então é uma coisa super difícil de você falar que o problema é esse, os problemas são vários, que agente procura de certa forma amenizar, mas e às vezes isso tudo vai desencadear a violência dentro do lar, com a familia, com a esposa, com os filhos (E6).

A violência é vista pelos profissionais e membros das equipes da ESF também como forma de expressão cultural de "educar" uma criança, passada de geração a geração, conforme é possível observarmos nas falas: Às vezes o motivo, éfalta de formação. Às vezes ele (o agressor) já no passado, na criação dele, ele já apanhou. Ele foi criado à base de pancada, então ele acha que criar os filhos também é na base da violência. Às vezes também a pobreza, a falta de dinheiro, a falta de emprego, eu acho que isso gera violência (E3).

\section{Procedimentos no atendimento à vítima de violência}

A terceira categoria mostra a atitude imediata dos sujeitos deste estudo diante da suspeita de violência como o contato ao Conselho Tutelar, o encaminhamento dos casos aos hospitais de referência ou a outros membros da mesma ESF e agir de forma multidisciplinar, o que pode ser ilustrado pelas seguintes falas: Chegamos a conversar com a criança; avaliar não, nem a examinar. A gente já encaminhou (E2). Teria que passar para frente (o caso de violência). Passaria para minha supervisora (enfermeira). Eu acho que no caso ela estaria levando para frente, para o Conselho Tutelar (E18).
A ação dos participantes deste estudo é permeada por dificuldades comuns a situações de violência, pois nem sempre a família permite uma clara identificação dos fatos e acontecimentos que geraram a agressão, silenciando-se diante da violência devido ao medo do agressor, a falta de confiança no profissional de saúde e nos membros das equipes da ESF, a vergonha diante da sociedade por estar vivendo essa situação e por não aceitar e não acreditar que o agressor seja um ente querido, tal como na fala a seguir: Acho que medo do próprio agressor também e vergonha para a sociedade, passar para os outros que está numa situação de aceitar aquilo ali (E16).

Além disso, o discurso dos membros das equipes da ESF expressa dificuldades, justificada pela necessidade do sigilo profissional e a falta de governabilidade diante da impunidade dos agressores e da lentidão na resolução pelo Conselho Tutelar, receio de represálias dos familiares e de prejudicar ainda mais a criança com alguma intervenção no caso. Esses aspectos parecem interferir substancialmente no modo como cada membro das equipes da ESF atua diante da violência, como ilustra a fala do entrevistado a seguir: Uma coisa que fica difícil para mim (conduta diante da violência infantil) e mais fácil para o lado da enfermagem, eu acho, por que o médico tem que preservar o segredo do paciente. Eu não posso pegar uma criança espancada e ligar para a delegacia da criança e falar olha, o pai da criança está batendo nela. Por que, eu estou infligindo o código médico da minha escola (E1).

\section{O caminho para ações preventivas}

Os dados articulados nesta categoria evidenciam uma possibilidade trazida pelos sujeitos do estudo como um caminho para que haja a prevenção da violência contra a criança, especialmente vinculada ao fortalecimento da relação entre pais e filhos. Por meio de suas falas os participantes do estudo sugerem 
que os pais devem tratar a criança com amor, atenção e carinho; manter um diálogo com a criança; criar os filhos dentro de princípios religiosos; oferecer melhores condições de vida para a criança, incluindo educação e lazer. A compreensão e paciência para com os filhos são vistas como caminho na prevenção da violência doméstica: Acho que isso ai é mais a formação mesmo da pessoa, quando pequena, em que os pais, têm que saber criar o filho, com amor, com carinho, de preferência numa religião, para poder ajudar (E3). E eu acho que prevenção é esclarecer, conversar, lá em casa a gente conversa muito, eu acho melhor, tanto que a gente vê esses casos com essas crianças, a maioria é falta de diálogo, não tem diálogo em casa, e assim quando a carência já há em casa faz com que elas às vezes sejam enganadas por uma pessoa na rua, que qualquer coisinha leva elas e assedia (E10).

\section{DISCUSSÃO}

Segundo a literatura (10-11), a violência doméstica compreende todo ato ou omissão praticada contra a criança ou o adolescente que possa causar prejuízos ao bem-estar e à integridade física, sexual e psicológica dos mesmos. Pode ser infringida dentro ou fora de casa por algum membro da família, incluindo pessoas que passam a assumir função parental, ainda que sem laços de consangüinidade aparentes. Implica, de um lado, uma transgressão do dever de proteção do adulto e, de outro, uma coisificação da infância, isto é, uma negação da liberdade e do direito que crianças e adolescentes têm de serem tratados como sujeitos e pessoas em condições peculiares de desenvolvimento.

Apesar de haver uma abordagem da violência contra a criança em um contexto econômico, político e social, a violência doméstica é a principal forma de manifestação da violência infantil, sendo a mais citada pelos profissionais e membros das equipes da ESF. É provável que ela seja mais visível aos participantes do estudo, por trabalharem diretamente com a família, inseridos em seu âmbito. Assim, com essa aproximação, tem melhor apreensão do contexto familiar, possibilitando-lhes construir vínculos, o que facilita a detecção da violência. Essa violência passa a ser vista de forma mais naturalizada por estar dentro do âmbito familiar em que o adulto por ter mais poder dentro da instituição família, passa a não considerar a criança, negando os seus direitos e a sua liberdade dentro da família, tendo então o papel apenas de obediência e assim, sendo tratados como coisas e não como pessoas em desenvolvimento.

Existem diversas causas da violência como a desestruturação familiar, desencadeados pelo desemprego, salários baixos, divórcios, falta de moradia, condições inadequadas de saúde e baixa escolaridade (12-13). Assim, é possível observar que grupos sociais economicamente menos favorecidos são sujeitos de violências, até mesmo por descaso social. Além disso, as crianças que sofreram agressões físicas têm mais propensão de quando se tornarem adultos baterem nos seus filhos (14).

Este comportamento passa por várias gerações e muitas vezes esses filhos, adultos, certamente agirão de forma semelhante com outras pessoas, sejam filhos, companheiros, ou outros. Assim, a violência se constitui como um fenômeno sociocultural relacionada intimamente às particularidades dos grupos sociais, ao modo dos indivíduos compreenderem (coletivamente), ao estabelecimento de regras e condutas, entre outros. Dessa maneira pode ser considerada ou não como um ato violento dependendo da cultura e da sociedade que o indivíduo está inserido, além do que é compreendido como um ato violento ou não.

O profissional de saúde e os membros das equipes da ESF necessitam estar apto para detectar e decodificar os sinais e sintomas entre crianças e adolescentes, vítimas de vio- 
lência. É necessário ouvi-los ao realizar seu exame clínico e tratamento. A capacitação se estende ao manejo psicológico e ao conhecimento da legislação e meios de proteção legais e sociais existentes em sua comunidade, como o Conselho Tutelar, o juizado da infância e os hospitais de referência, de forma que possam realizar encaminhamentos a esses locais, prestando melhor assistência as vítimas (15). Estudo mostra que um trabalho multidisciplinar, interdisciplinar e intersetorial é fundamental para lidar com a problemática (16).

Todavia, muitas vezes as ações no sentido de comunicar outro órgão, seja o Conselho Tutelar, outras instituições ou profissionais, reduzem-se a uma forma de passar o problema adiante, considerando o desconhecimento sobre como proceder diante do fato. Essa ação pode ser equivocadamente entendida como sendo de âmbito multidisciplinar, muito embora não possa ser assim considerada. É um "passar adiante" que apenas pretende respaldar o profissional e o membro das equipes da ESF diante do fato.

Além disso, tem-se notado que a interferência na dinâmica familiar, fundamental na assistência aos casos de violência doméstica, pode não ser sempre bem aceita pela família (17).

Portanto, a família contribui para que a violência doméstica contra a criança permaneça velada no âmbito familiar, dificultando sua identificação; assim, é importante que o medo e a vergonha sejam superados de modo que as vítimas sejam socorridas e as consequências não sejam tão graves, a ponto, por exemplo, de levar à morte.

As crianças apontam que vínculos de amor e afeição são mais significativos para seu desenvolvimento do que os vínculos familiares, estabelecidos por meio de consanguinidade (18). Há benefícios na convivência em um ambiente não violento, onde, provavelmente, outros padrões de relacionamentos, mais compreensivos e dialógicos, são acessados como estratégias de solução de problemas. Sem dúvida, a atmosfera familiar afetiva é uma das questões que mais incrementa a vida saudável de uma criança, podendo, inclusive, protegê-la de problemas frequentes e inerentes ao seu cotidiano (19).

A prevenção da violência contra a criança envolve a relação e o vínculo entre pais e filhos, uma vez que, muitas vezes, por ser gerada em casa, é também de responsabilidade dos pais a promoção do desenvolvimento saudável dessas crianças.

Considerando que os profissionais e os membros das equipes da ESF trabalham junto às famílias de sua área adstrita, sua visão da violência, muitas vezes, pode estar limitada à percepção da família e dos cuidados dos pais, os quais entendem caber-lhes a responsabilidade de prover a saúde para seus filhos. Não se referiram aos diversos fatores que influenciam a qualidade de vida da criança, como o contexto social no qual vive.

\section{CONSIDERAÇÕES FINAIS}

Os objetivos que nortearam o estudo de compreender os significados da violência atribuídos pelos profissionais e os membros das equipes da ESF a criança e o adolescente e suas atitudes diante de situações concretas no atendimento dessa clientela, possibilitaram a apreensão dos aspectos que envolvem a dinâmica do processo de ação desses sujeitos diante da violência.

Os profissionais e os membros das equipes da ESF significam a violência contra a criança, principalmente, como violência doméstica em suas variantes física e sexual, além da negligência. Além disso, destacam as questões sociais como o desemprego, a falta de planejamento familiar, pobreza, entre outros, como os principais motivos para que ocorra a violência no âmbito das famílias.

Outro agravante apontado pelos sujeitos foi a falta de conhecimento, medo de represália dos familiares e de fazer denúncia in- 
fundada, entre outros fatores. Essa situação mostra a importância do profissional de saúde e membros das equipes da ESF estar atento na detecção de que uma criança está sendo vítima de atos violentos e o discernimento e a responsabilidade de notificar os casos mesmo que estes sejam apenas suspeitas. Para isso, é fundamental que tanto o profissional e o membro das equipes da ESF, quanto as instituições formadoras e os serviços se preocupem em incluir, no processo de formação e capacitação desses profissionais, conhecimentos que lhes permitam mais assertividade diante do problema da violência infantil. A capacitação específica e mais adequada pode evitar que os casos dessa natureza sejam negligenciados e se agravem pela demora na assistência, já que muitas vezes, são passados adiante sem os devidos encaminhamentos ou soluções.

Apesar de entraves para a resolução da problemática da violência infantil, os entrevistados conseguem perceber caminhos de ações preventivas como orientações aos familiares de como educar e se relacionar com seus filhos, mantendo um vínculo de amizade e compreensão com a criança e o adolescente.

Ao compreendermos e discutirmos sobre a percepção da violência contra a criança segundo os profissionais de saúde e membros das equipes da ESF e suas ações diante dessa problemática, percebemos a possibilidade de adicionarmos, na área da saúde, incluindo a enfermagem, uma nova visão de abordar a violência infantil dentro dos princípios do Sistema Único de Saúde (SUS), que envolvem universalidade, ou seja, o cuidado de todas as crianças independentes da raça, cor e condições sociais; a integralidade, observando a criança em seus contextos biológico, psicológico e social, possibilitando que seu atendimento assegure a promoção, proteção e recuperação da saúde; a equidade, tratando os desiguais de forma desigual, ou seja, ajudando as crianças menos favorecidas para que se igualem àquelas que tenham melho- res condições ou que vivam em uma situação de convivência familiar mais favorável; à hierarquização nas quais os problemas que não conseguem ser resolvidos nas Unidades Básicas de Saúde, como alguns casos de violência, ao invés de serem esquecidos e ou abandonados, sejam encaminhados a outros níveis, como o hospitalar, de forma a resolver a situação de violência vivenciada pela criança. Todas essas ações devem ser realizadas focando a resolutividade dos casos, estando, para tal, aptos, dentro dos seus limites de complexidade. Os membros das equipes da ESF podem ainda atuar junto a outros órgãos ou instituições, como escolas e igrejas, para que resolvam os casos de violência.

Assim, este estudo ao responder aos seus propósitos nos possibilitou também destacar a importância desses profissionais de saúde e membros das equipes da ESF perceberem os usuários de forma integral dentro do contexto biológico, psicológico e social, além de observar questões individuais, promovendo melhores condições de vida à criança e ao adolescente.

\section{REFERÊNCIAS}

1. Pesce R. Violência familiar e comportamento agressivo e transgressor na infância: uma revisão da literatura. Cien Saude Colet. 2009;14(2):507-18.

2. Martins CBG, Jorge MHPM. A violência contra crianças e adolescentes: características epidemiológicas dos casos notificados aos Conselhos Tutelares e programas de atendimento em município do Sul do Brasil, 2002 e 2006. Epidemiol Serv Saude. 2009;18(4):315-34.

3. Barbosa PZ, Pegoraro RF. Violência doméstica e psicologia hospitalar: possibilidades de atuação diante da mãe que agride. Saude Soc. 2008;17(3):77-89.

4. Dossi AP, Saliba O, Garbin CAS, Garbin AJI. Perfil epidemiológico da violência 
física intrafamiliar: agressões denunciadas em um município do Estado de São Paulo, Brasil, entre 2001 e 2005. Cad Saude Publica. 2008;24(8):1939-52.

5. Lei n. 8.069 de 13 de julho de 1990 (BR). Dispõe sobre o Estatuto da Criança e do Adolescente (ECA). Diário Oficial da União [periódico na internet]. 16 jul 1990. [citado em: 17 jan 2010]. Disponível em: http://www010.dataprev.gov.br/ sislex/paginas/33/1990/8069.htm

6. Algeri S, Souza LM. Violência contra crianças e adolescentes: um desafio no cotidiano da equipe de Enfermagem. Rev Lat Am Enfermagem. 2006;14(4):62531.

7. Tanaka OY, Ribeiro EL. Ações de saúde mental na atenção básica: caminho para ampliação da integralidade da atenção. Cien Saude Colet. 2009;14(2):477-86.

8. Minayo MCS. Violência um velho-novo desafio para a atenção à saúde. Rev Bras Educ Med. 2008;9(1):55-63.

9. Bardin L. Análise de conteúdo. Lisboa: Persona; 1979.

10. Guerra VNA. Violência de pais contra filhos: a tragédia revisitada. $4^{\text {th }}$. ed. São Paulo: Cortez; 2001. 264 p.

11. Ministério da Saúde (BR). Violência intrafamiliar: orientações para a prática em serviço. Brasília (DF): Ministério da Saúde; 2001.

12. Nunes CB, Sarti CA, Ohara CVS. Concepções de profissionais de saúde sobre a violência intrafamiliar contra a criança e o adolescente. Rev Lat Am Enfermagem. 2008;16(1):136-41.

13. Pierantoni LMM, Cabral IE. Crianças em situação de violência de um ambulatório do Rio de Janeiro: conhecendo seu perfil. Esc. Anna Nery. 2009;13(4):699707.

14. Chung EK, Mathew L, Rothkopf AC, Elo IT, Coyne JC, Culhane JF. Parenting attitudes and infant spanking: the influence of childhood experiences. Pediatrics. 2009; 124(2):278-86.

15. Pfeiffer LS, Salvagni EP. Visão atual do abuso sexual na infância e adolescência. J Pediatr (Rio J). 2005;81 (Suppl 5):197204.

16. Ferreira AL. Acompanhamento de crianças vítimas de violência: desafio para o pediatra. J Pediatr (Rio J). 2005;81 (Suppl 5):173-80.

17. Ferreira AL, Schramm FR. Implicações éticas da violência doméstica contra a criança para profissionais de saúde. Rev Saude Publica. 2000;34(6):659-65.

18. Martins CS, Ferriani MGC, Silva MAI, Zahr NR, Arone KMB, Roque EMST. Family dynamics from the perspective of parents anda children involved in domestic violence against children and adolescents. Rev Lat Am Enfermagem. 2007;15(5):889-94.

19. Avanci JQ, Assis SG, Santos NC, Oliveira RVC. Escala de violência psicológica contra adolescentes. Rev Saude Publica. 2005; 39(5):702-8. 